\title{
Implantação do Pacto Nacional pela Alfabetização na Idade Certa em Sergipe: estratégias formativas e avaliadoras
}

\author{
Silvana Aparecida Bretas \\ José Ricardo Carvalho
}

\section{Resumo}

O processo de formação continuada do Pacto Nacional pela Alfabetização na Idade Certa (PNAIC), em Sergipe, será analisado com base nos relatórios elaborados pelos orientadores de estudo para verificar se a formação continuada transformou o saber alfabetizador dos professores e possibilitou novos processos metodológicos de ensino. Três critérios orientaram a seleção dos relatórios: 1) um município em cada macrorregião; 2) relatórios de 2013, 2014 e 2015; 3) provenientes de escolas públicas municipais e estaduais. Não é possível afirmar que houve uma transformação das práticas de alfabetização na perspectiva do letramento, mas os relatórios revelam as ressignificações que os docentes fazem de suas práticas no $1^{\circ}, 2^{\circ}$ e $3^{\circ}$ ano do ensino fundamental.

Palavras-chave: formação continuada; política pública; alfabetização; letramento; prática educativa. 


\section{Abstract \\ Implementation of the Pacto Nacional pela Alfabetização na Idade Certa in Sergipe: analysis of the study advisors' reports.}

The process of continuing education of the Pacto Nacional pela Alfabetização na Idade Certa (PNAIC), in the Brazilian state of Sergipe, will be analyzed on the reports formulated by the study advisors in order to verify whether the continuing education transformed teachers' literacy knowledge and made new methodological processes of teaching possible. Three criteria directed the selection of the reports: 1) one municipality in each micro-region; 2) reports from 2013, 2014 and 2015; 3) produced in municipal or state public schools. It cannot be asserted that a transformation of the literacy practices happened, yet the reports reveal that teachers re-signified their practices in the $1^{\text {st }}, 2^{\text {nd }}$ and $3^{\text {rd }}$ years of elementary school.

Keywords: continuing education; public policy; literacy knowledge; literacy; educational practice.

\section{Introdução}

O Pacto Nacional pela Alfabetização na Idade Certa (PNAIC) é uma política pública, originada em 2012, que promoveu a união de esforços do Ministério da Educação (MEC), das universidades públicas e das secretarias de educação estaduais e municipais para fortalecer o trabalho pedagógico do processo de alfabetização desenvolvido nas escolas de ensino fundamental. Em Sergipe, como política pública, teve convênio firmado entre o MEC, a Universidade Federal de Sergipe (UFS), a Secretaria Estadual de Educação e as secretarias municipais de educação de 74 municípios. O objetivo principal desse acordo foi contribuir para a formação continuada de professores alfabetizadores que atuavam diretamente com crianças de seis a oito anos. A Portaria MEC nº 867/2012, que institui o PNAIC, determina os quatro eixos que as ações entre os entes envolvidos devem apresentar:

\footnotetext{
Art. $6^{\circ}$ As ações do Pacto compreendem os seguintes eixos:

I formação continuada de professores alfabetizadores;

II materiais didáticos, literatura e tecnologias educacionais;

III avaliação;

IV gestão, controle social e mobilização. (Brasil. MEC, 2012).
}

Este artigo apresenta um estudo de caso sobre um programa de formação continuada destinado a professores alfabetizadores, tendo como base as experiências desenvolvidas pela UFS na implantação do PNAIC sob a tutela do MEC, em 2013, 2014 e 2015. Anteriormente, propostas de formação alfabetizadora em Sergipe, como o Pró-Letramento, foram implementadas por universidades de outros estados - Brasília e Pernambuco. Sendo assim, será analisado o processo de implantação 
do Pacto, bem como as estratégias formadoras e avaliadoras realizadas por toda a equipe de formadores da UFS, orientadores de estudo e alfabetizadores, tendo os autores participado desse processo na qualidade de coordenadora adjunta, desde 2014, e coordenador geral, desde 2012.

O processo de alfabetização envolve desde a dimensão das políticas públicas gestadas pelo Estado até a ação do professor em sala de aula, sendo, portanto, de alta complexidade. Por essa razão, o tema deste trabalho será abordado em três aspectos:

1) desafios de implementar uma política pública educacional da dimensão do PNAIC no estado de Sergipe;

2) transformações ocorridas na concepção e na implementação da política para formação inicial e continuada de professores alfabetizadores;

3) análise do processo de formação continuada do PNAIC implantado pela UFS por intermédio dos relatórios dos orientadores de estudo.

Ao iniciar o trabalho de congregar os Departamentos de Educação dos campi de São Cristóvão e de Itabaiana da UFS para a efetivação do PNAIC, de imediato, percebemos o trabalho político que se descortinava, pois seria necessário não só dialogar com secretários municipais e com o secretário estadual para a mobilização de suas respectivas redes, mas também programar e estruturar um trabalho de formação continuada que cumprisse o desafio assumido.

A fim de fortalecer nossos argumentos e de convencer as forças políticas do Estado a contribuírem com o programa de formação, fizemos um breve levantamento do nível educacional da população sergipana por meio do Mapa do analfabetismo no Brasil (Brasil. Inep, [2002?]), que nos revelou o percentual da população sem atendimento educacional e também nos permitiu inferir a existência de uma prática pedagógica caracterizada pela repetência e, consequentemente, pelo abandono escolar. Verificamos, então, a absoluta necessidade de agir na formação continuada de professores, visando conter minimamente tal quadro.

Sabíamos da existência, nas redes públicas, de políticas de implantação de programas de alfabetização elaborados por empresas privadas, que, devido a sua natureza prescritiva para a formação de professores, passaram a ser denominadas como "pacotes educacionais". Naturalmente, os sindicatos de professores fizeram forte resistência a esse tipo de política e, ao receberem a notícia do programa de formação, mesmo antes de iniciarmos as atividades, supuseram que se tratava dos mesmos pacotes educacionais. Essa situação nos demandou visitas às várias escolas de diferentes municípios, a fim de nos reunirmos com seus respectivos alfabetizadores e representantes sindicais. Esse momento inicial nos deu a dimensão do quão difícil seria a adesão dos secretários municipais e dos profissionais das redes públicas. Ao longo dos três anos, tais dificuldades foram, aos poucos, diminuindo, na medida em que a formação continuada se estabeleceu como importante processo de mudança nas práticas de alfabetização que relataremos mais adiante. 
Com base nas leituras dos cadernos ${ }^{1}$ elaborados pela equipe de professores universitários e colaboradores sob a supervisão do MEC, passamos a compreender que o PNAIC procurava anteceder a política de cooperação entre os entes federados prevista na regulamentação do Plano Nacional de Educação (PNE), em relação ao Sistema Nacional de Educação (Brasil, 2014). Nesse sentido, o PNAIC foi compreendido como um esforço necessário para a integração do sistema de ensino que encerra tantas diferenças sociais, regionais e econômicas.

A segunda compreensão que passamos a sustentar foi a de que o PNAIC também atuava no plano da micropolítica, tendo em vista que oferecia formação continuada para os orientadores de estudo que, por sua vez, reelaboravam a propostas de formação para professores alfabetizadores das redes públicas. A partir dos estudos e debates realizados pela equipe de formação, foi possível nos apropriarmos mais da tessitura teórica do programa e, então, passamos a defender a ideia de que o PNAIC não era um pacote educacional. Entendíamos que se tratava de uma política de pactuação entre os entes federados: a União, o Distrito Federal, os estados e os municípios brasileiros, os quais, pela Constituição Federal (1988), são autônomos e, mesmo pactuados em somar esforços para alfabetizar suas crianças até oito anos de idade, tinham a liberdade de assumir ou não as ações do Pacto (Brasil, 2012). No estado de Sergipe, a Secretaria do Estado da Educação e as demais secretarias municipais aderiram ao pacto integralmente, exceto a capital do estado e a cidade de Aquidabã que aderiram ao pacto nacional, mas não às ações do PNAIC.

Outro aspecto importante da referida política é sua estrutura complexa e muito ampla, visando à formação de todos os professores alfabetizadores das redes públicas. Foram definidos cursos presenciais com duração de dois anos e carga horária de 120 horas anuais para a formação de orientadores de estudo que, por sua vez, participaram de cursos com os professores formadores (professores das IES). Em seus locais de trabalho, desenvolveram a formação com os alfabetizadores, pois a função dos orientadores de estudo era serem multiplicadores da formação em suas escolas.

A metodologia referenciada originou-se da experiência do Programa de Formação Continuada de Professores dos Anos/Séries Iniciais do Ensino Fundamental (Pró-Letramento), que visava à integração de teoria e prática, por isso, era recomendável que os orientadores de estudo tivessem sido tutores formados pelo Pró-Letramento do estado ou do município (Brasil. MEC. SEB. 2012b, p. 39). Todos os segmentos de profissionais da educação receberam bolsas de estudo nos valores e critérios definidos na Resolução FNDE/CD n 24/2010 (Brasil. FNDE, 2010).

Nesse ponto, destaca-se também o papel da universidade na formação continuada de professores, uma vez que a atual Lei de Diretrizes e Bases (Lei $n^{\circ}$ 9.394/96) consolidou o direito de formação continuada dos profissionais

${ }^{1}$ Os cadernos de alfabetização, alfabetização matemática, alfabetização em língua portuguesa, e formação de professores estão disponíveis em: <http://pacto.mec.gov.br/2012-09-19-19-09-11>. 
da educação. A universidade pública, ao ser chamada para assumir o protagonismo dessa política, acentuou seu caráter de instituição social responsável pelo patrimônio da escola pública e popular. O que não significou o aceite cego e irrestrito das demandas políticas nacional e local, mas a ocupação de um espaço legítimo de formação.

\section{A construção da formação continuada}

O objetivo da proposta de formação organizada pela universidade partiu da escuta dos professores, considerando-os com sujeitos construtores de práticas letradas vivenciadas na dinâmica escolar. O paradigma assumido apostava na autonomia do professor e na transformação das relações de ensino-aprendizagem durante os anos iniciais do ensino fundamental, considerando os conteúdos da alfabetização articulados ao domínio do sistema de escrita alfabético com as práticas sociais da cultura escrita (letramento). No caderno de apresentação da formação do professor alfabetizador (Brasil. MEC. SEB, 2012a, p. 33), encontramse os conceitos fundantes da formação continuada, sintetizados a seguir:

1) Currículo, concepção de alfabetização e avaliação;

2) Planejamento e organização de rotinas na alfabetização;

3) Apropriação do sistema alfabético de escrita e consciência fonológica;

4) A ludicidade na alfabetização; jogos na alfabetização;

5) Textos na alfabetização;

6) Projetos e sequências didáticas na alfabetização;

7) Heterogeneidade na alfabetização e projetos para crianças que não estão atendendo às expectativas;

8) Progressão escolar, avaliação e organização do trabalho docente.

Diante dos objetivos e conteúdos propostos, inseriam-se proposições de práticas curriculares visando à efetivação dos elementos acima nas oficinas de formação. Esse processo exigiu um amplo diálogo entre diferentes instâncias formativas - universidade, secretarias de educação, coordenadores locais, orientadores de estudo e professores -, para configurar os fenômenos de ensinoaprendizagem da leitura e da produção de texto, tendo como ponto de partida os saberes que os alunos já possuem e aqueles que são potencialmente capazes de aprender, no sentido de garantir o direito de participação social no universo da cultura oral e escrita.

Para isso, foi necessário ultrapassar os muros das escolas e investigar as práticas sociais da oralidade da comunidade local que mobilizam as tarefas a serem desempenhadas no cotidiano dos professores e dos alunos. 
De acordo com os aspectos da realidade que mereciam atenção mais cuidadosa, a equipe do PNAIC-SE definiu três pontos sobre os quais deveriam concentrar a formação continuada:

a) Correção idade/série - fluxo escolar que representa o descompasso entre a idade da criança e a série que frequenta. Era necessário pensar em atender crianças acima de oito anos de idade que ainda se encontravam no ciclo de alfabetização.

b) Alfabetizar todas as crianças até os oito anos de idade, garantindo-lhes a permanência na escola e cultivando práticas de letramento.

c) Estreitar a relação entre a universidade e a escola de educação básica para oportunizar encontros planejados entre os professores dessas instituições.

Práticas que rompessem com o paradigma da leitura como decodificação e da produção escrita como cópia precisavam de tempo para se consolidarem em fazer pedagógico. A construção de uma rotina que garantisse um ambiente alfabetizador em língua portuguesa precisava de ações contínuas de planejamento e acompanhamento, a fim de observar seu grau de interação com os alunos e o exame de novas possibilidades de aprendizagem por meio de textos com função social.

A estratégia pedagógica foi realizar encontros, adaptados à realidade de cada 72 região, entre formadores, orientadores de estudo e coordenadores locais. Os encontros de troca ocorreram em diferentes esferas:

a) encontro de professores da universidade com seus pares, para discutir as ações da formação;

b) professores da universidade com os orientadores de estudo; e

c) orientadores de estudo com os alfabetizadores.

O modelo de formação escolhido possibilitou a adoção de uma perspectiva reflexiva sobre as práticas alfabetizadoras propostas nos cadernos de formação do PNAIC (Brasil. MEC. SEB, 2012a). O material foi utilizado como ponto de partida para gerar o diálogo sobre as próprias práticas desenvolvidas pelos professores. Não houve transposição direta dos conceitos e dos procedimentos trabalhados nas formações, visto que as condições e as realidades vividas pelos professores eram de diferentes bases de conhecimentos.

Para aprimorar o trabalho de alfabetização nas salas de aula sergipanas, enfatizamos o planejamento de sequências didáticas e a reflexão sobre o funcionamento do sistema de escrita alfabética, com uma abordagem que valorizasse as práticas sociais da cultura escrita, em situações nas quais se evidenciassem os usos reais da escrita como forma de interação e compreensão da realidade vivida. 
Para examinar os avanços obtidos na formação, propôs-se a produção de relatórios que descrevessem o processo de formação junto aos alfabetizadores, bem como as atividades realizadas nas classes de alfabetização. Alfabetizadores, supervisores e orientadores de estudo elaboraram o relatório em conjunto, levando em conta as seguintes questões levantadas pela coordenação pedagógica da Universidade:

1) Como foram planejadas as atividades de estratégias de leitura e produção de texto com os alfabetizadores? Quais os textos utilizados na leitura deleite? Que estratégias de interdisciplinaridade foram utilizadas pelos professores? Que atividades de leitura bem-sucedidas foram apresentadas pelos professores? Quais foram as dificuldades na organização da rotina sob a perspectiva construtivista? Como foi a apresentação da avaliação diagnóstica e formativa entre os alfabetizadores? Como foi trabalhado o eixo da oralidade? Que situação concreta de trabalho com a oralidade pode ser exemplificada?

2) Os professores em seu planejamento têm preenchido o quadro de rotina? Que atividades têm aparecido no quadro de rotina dos professores na dinâmica do letramento?

3) Os professores têm conseguido trabalhar com os quatro eixos de aprendizagem a partir dos direitos de aprendizagem? Que sequências didáticas e projetos foram desenvolvidos pelos professores?

4) Como tem sido a troca de informações e experiências entre os professores com os alunos e entre os profissionais da educação? Relate.

Junto ao relato das ações realizadas a partir da formação desenvolvida na Universidade, pedíamos que cada supervisor da rede realizasse uma autoavalição da unidade trabalhada no que se refere aos avanços sobre o domínio dos direitos de aprendizagem.

Considerando o planejamento territorial do estado de Sergipe, ${ }^{2}$ cujo modelo é adotado pela Secretaria Estadual de Educação, as turmas de orientadores de estudo foram formadas de modo a atender as especificidades regionais de distância e localização de cada município. Assim, distribuímos os orientadores em sete turmas, divididas em dois polos. Na cidade de Itabaiana, foram agrupados os orientadores oriundos dos municípios geograficamente situados no Sertão, Agreste e Sul-Agreste, totalizando três turmas. No polo de São Cristóvão, foram agrupadas mais quatro turmas provenientes da capital, litoral norte e litoral sul do estado. Essa organização facilitou o deslocamento dos orientadores, de modo a garantir sua frequência nos

${ }^{2}$ Documento que estabelece as macrorregiões do estado em: a) Alto Sertão Sergipano; b) Médio Sertão Sergipano; c) Baixo São Francisco; d) Leste Sergipano; e) Agreste Central Sergipano; f) Grande Aracaju; g) Centro Sul Sergipano; h) Sul Sergipano (cf. Sergipe. Seplag, 2007). 
encontros. Os supervisores assumiram a função de acompanhar e avaliar o desenvolvimento da formação, auxiliando orientadores, alfabetizadores e coordenadores a preencherem as inscrições, os relatórios e as avaliações no Sistema de Monitoramento do PNAIC (Sispacto). Para a efetivação do acompanhamento dos cursistas, fez-se necessária a entrega periódica de relatórios das unidades - conforme previsto nos cadernos do Pacto dos cursistas dos municípios e do estado -, via e-mail, CD-ROM ou até impressos na mesma periodicidade das formações.

\section{Relato dos primeiros encontros}

Ao iniciar o primeiro ano de formação continuada, a equipe de coordenação e de formadores realizou uma série de encontros para elaborar as oficinas pedagógicas fundamentadas nos Cadernos de Formação do PNAIC, ${ }^{3}$ assim estabelecemos os seguintes princípios gerais que perpassassem a proposta e que pudessem reger a organização das oficinas:

- Currículo para inclusão, isto é, compromisso com a aprendizagem de todas as crianças.

- Alfabetização na perspectiva dos direitos de aprendizagem (objetivos e conteúdos).

- Acompanhamento da aprendizagem das crianças (avaliação) para o planejamento das ações.

- Integração entre diferentes componentes curriculares (matemática, português e outras áreas de conhecimento).

- Ensino sistemático e planejamento da ação didática: a) apropriação do sistema alfabético da escrita; b) leitura e produção de textos escritos; c) oralidade.

- Professor como profissional ativo, reflexivo e autônomo.

Nossa expectativa era alimentar uma reflexão contínua sobre o fazer pedagógico, a fim de intensificar a dinâmica do projeto pedagógico da escola e de projetos didáticos na sala de aula, buscando romper com uma proposta de ensino mecanicista e fragmentada em um conjunto de técnicas e disciplinas. O novo enfoque preocupa-se com o modo como o sujeito aprende e de que forma o professor pode mediar esse processo de forma interdisciplinar, lúdica e reflexiva, de acordo com as estratégias descritas no caderno de apresentação da formação do professor alfabetizador (Brasil. MEC. SEB, 2012a).

\footnotetext{
${ }^{3}$ Em 2012, recebemos oito unidades de cadernos de cada ano do ciclo de alfabetização, três cadernos de educação inclusiva, oito unidades de cadernos de educação do campo e três de classes multisseriadas.
} 


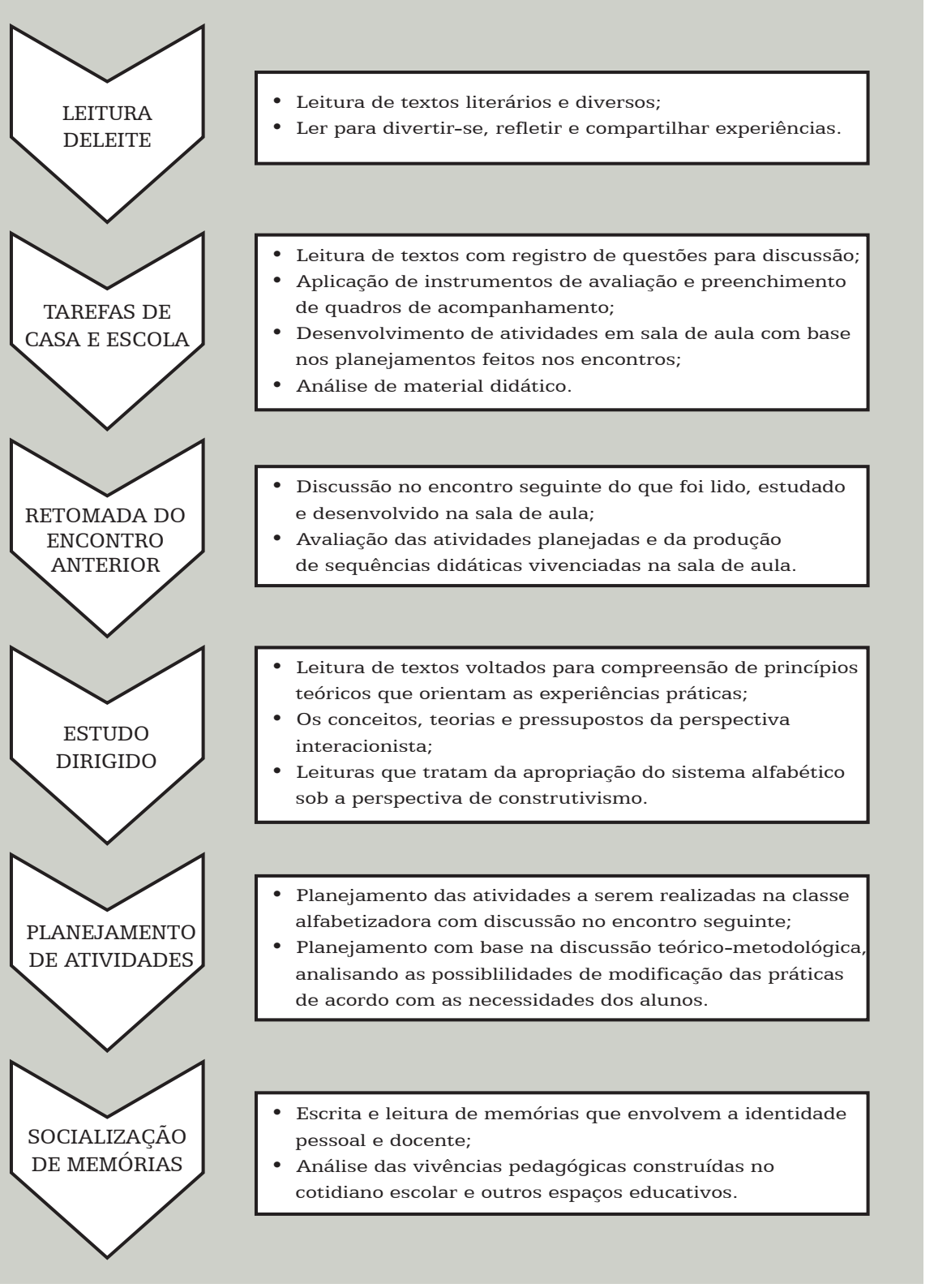

Figura 1 - Estratégias permanentes da formação

Fonte: Slides produzidos pela equipe de formadores, 2013.

A proposta de formação docente deveria ajudar o professor a organizar uma rotina de ações que estimulassem o desenvolvimento da leitura e da produção de texto, considerando as noções de gênero textual, sequência didática e projeto didático.

Era preciso construir percursos diferenciados para cada ano escolar do ciclo, a fim de que as atividades não se repetissem. Nesse sentido, algumas propostas foram comuns a todos os professores, pois se trata de uma filosofia teóricometodológica conjunta, que buscava coerência e unidade de trabalho. Ao mesmo 
tempo, procurávamos atividades específicas para cada ano, a fim de aprofundar aspectos que teriam continuidade de forma mais complexa em momentos posteriores.

\section{Análise dos relatórios dos orientadores de estudo}

Para realizar a análise dos relatórios dos orientadores de estudo, optamos pela modalidade qualitativa de investigação, a fim de criar categorias que permitissem inferir sobre as possíveis transformações operadas pela formação continuada nas práticas educativas dos professores alfabetizadores e dos seus respectivos alunos. Para tanto, esclarecemos que foi necessário selecionar, entre o volumoso material produzido pelos orientadores de estudo, relatórios representativos do universo de formação nos anos de 2013, 2014 e 2015. Assim, procedemos ao estabelecimento dos seguintes critérios:

1) um município em cada macrorregião;

2) relatórios que contemplassem os anos de 2013, 2014 e 2015;

3) relatórios de escolas públicas municipais e escolas públicas estaduais.

O cruzamento de tais critérios resultou numa amostra representativa de diferentes regiões sergipanas, dos anos em que foram desenvolvidas as atividades de formação continuada e, ainda, de ambas as redes. Vale registrar que tal procedimento metodológico visava garantir escolhas equitativas diante do grande volume de relatórios existentes.

Para fim de análise do conteúdo dos referidos relatórios, estabelecemos categorias de ordem pedagógica conforme as estratégias básicas da formação continuada, a saber:

a) condições do desenvolvimento da formação;

b) existência ou não de avaliação diagnóstica; e

c) desenvolvimento dos eixos de leitura, oralidade, produção textual e análise linguística.

\section{Condições do desenvolvimento da formação}

Na primeira categoria, observamos que as condições de realização da formação do professor alfabetizador, em seu local de trabalho, dizem respeito às condições materiais e à infraestrutura para a reunião dos professores e, além disso, a própria dinâmica dos encontros pode representar avanços ou dificuldades de desenvolvimento do conteúdo proposto. Assim, vejamos o que foi registrado nos relatórios. ${ }^{4}$

Os direitos de aprendizagem do PNAIC não foram comparados com a proposta curricular da rede, na maioria das escolas, por não localizarem o Projeto Político

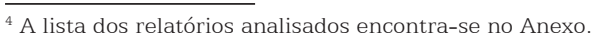


Pedagógico (PPP) da escola. Em algumas em que se conseguiu ver e comparar, pouco tem a ver com o que estamos trabalhando. (Relatório de Canindé de São Francisco, 2013a).

O que ainda precisa ser feito, de acordo com as questões apresentadas e as dificuldades para a execução das atividades propostas pelo PNAIC, são as salas de aulas repletas, pois o tempo do professor disponível é muito pouco para planejar a realização dessa atividade. Alguns sentem muitas dificuldades em trabalhar com as turmas, principalmente, com a oralidade e a análise linguística dos seus alunos, além de os anexos serem poucos para exemplificar. Mesmo assim, nos sentimos ansiosos e esperançosos de que isto venha a mudar. (Relatório de Canindé de São Francisco, 2013b).

O contexto de implantação da formação continuada de alfabetizadores apresentava fragilidades e ausências na organização do trabalho pedagógico nas escolas participantes, fazendo refletir sobre como contribuir para o avanço de novas sistematizações do processo de ensino e para a elaboração do projeto pedagógico da escola. Essas características também apareceram em outro relatório:

Por ser algo novo, e toda mudança exige adaptações, precisa-se de total empenho e adaptações, pois devido ao constante uso dos métodos tradicionais de ensino causam hábitos que exigem esforços. (Relatório de Feira Nova, 2013)

Apesar de algumas imprecisões dessa citação, é possível inferir que a concepção de alfabetização na perspectiva do letramento defendida pelo PNAIC era pouco conhecida e encontraria resistência. Assim, o princípio de respeitar e dialogar com os conhecimentos já assimilados pelos professores foi imprescindível para que pudéssemos avançar nos propósitos da formação. Uma estratégia para conservar esse diálogo era recuperar a memória do processo de alfabetização do próprio professor:

Em seguida, os cursistas fizeram relatos sobre a maneira que alfabetizados e sobre as experiências das salas de aula. (Relatório de Amparo de São Francisco, 2013).

Chega a hora de compartilharmos experiências e memórias da infância que reportem aos momentos em que as professoras foram alfabetizadas. Muitas lembranças vieram à tona: boas e más. Emocionadas, lembram a felicidade das descobertas ou os bloqueios sofridos. Nesse instante toda a turma passa a refletir sobre a importância do professor nos primeiros anos de escolarização. (Relatório de Nossa Senhora do Socorro, 2013).

Refletir, compartilhar e registrar foram passos fundamentais para demarcar o ponto de partida da feitura teórica e prática do processo alfabetizador na perspectiva do letramento. No entanto, há de se considerar que os professores alfabetizadores, ao registrarem suas experiências, fazem-no de forma bastante genérica, resumida e pouco detalhada. Ainda assim, os relatórios são indicativos de como foram realizadas as formações e, para mergulhar mais no universo da sala de aula, foi preciso observar as fotos e o planejamento de cada professor e, assim, dimensionar melhor as possíveis mudanças da prática alfabetizadora no processo da formação continuada. 
Com relação à avaliação diagnóstica, observamos a seguinte passagem:

Explico então, os Direitos de Aprendizagem em Língua Portuguesa enfatizando o Eixo Leitura, apresento as fichas de acompanhamento: Perfil da turma e a individual de Leitura que são levadas para casa para serem preenchidas e entregues. Provoco a discussão sobre o foco no aluno: O que ele sabe? O que precisa saber? O que o professor deve fazer para garantir o direito de aprendizagem de todos os alunos? O que deve ser ensinado nas turmas do terceiro ano? (Relatório de Nossa Senhora do Socorro, 2013).

Iniciou-se, então, o primeiro passo para desmontar a carcomida fórmula do certo e do errado e da supremacia da avaliação de resultado. Estava posta a necessidade de análise da produção da escrita de cada criança e a reflexão sobre como intervir pedagogicamente de modo necessário e compatível ao nível de compreensão dos pequenos estudantes. Ainda, no mesmo processo, a orientadora de estudo enfatiza outros momentos da formação:

Após as discussões, entramos no texto Avaliação para a inclusão: alfabetização para todos, através de resumo em slides, identificamos os principais objetivos da avaliação, pois é necessário enfatizar que ela perpassa toda a ação pedagógica, do planejamento a sua execução. Foi compreendido que a intervenção feita pelo professor deve ter como base os resultados das avaliações realizadas durante todo o processo de aprendizagem do aluno. Identificamos também que a avaliação deve ser formativa para que possamos ajustar nossas estratégias didáticas a cada situação encontrada e que também nos possibilite planejar de forma segura para atender a todos os níveis de aprendizagem. No Compartilhando, os professores foram convidados a analisarem o instrumento de avaliação sugerido pelo Portal do MEC, para identificarem os direitos de aprendizagem que estão contemplados nele. Como tarefa de casa, os professores deveriam terminar o preenchimento das fichas de acompanhamento e a análise (sic) do PPP da escola. (Relatório de Nossa Senhora do Socorro, 2013).

A ideia de avaliação formativa começava a ganhar corpo teórico e prático para auxiliar os alfabetizadores a realizarem suas análises, no intuito de retroalimentar suas ações, para garantirem a aprendizagem ainda não consumada pelos estudantes, a partir de situações contextualizadas na forma de projetos e sequências didáticas. Foi incorporada a ideia de escolher os textos a serem trabalhados na sala de aula, considerando os projetos desenvolvidos na escola. No município de Lagarto, os professores desenvolveram o projeto "Lixo é progresso".

É possível observar a valorização das formas de registro realizado pelos alunos como atividade diagnóstica e produção de conhecimento. Por meio dessas atividades, o professor pôde investigar o que eles já dominavam em termos do sistema de escrita alfabética e modo de organização dos textos que produzem. Com base nas observações realizadas pelos alunos na visita ao lixão, foram elaboradas representações gráficas para relatarem o que viram, demonstrando o que compreenderam no processo interacional.

Os textos espontâneos produzidos pelos alunos passaram a ser um elemento indicativo dos saberes que eles ainda precisavam internalizar para ler e escrever textos de forma proficiente. 


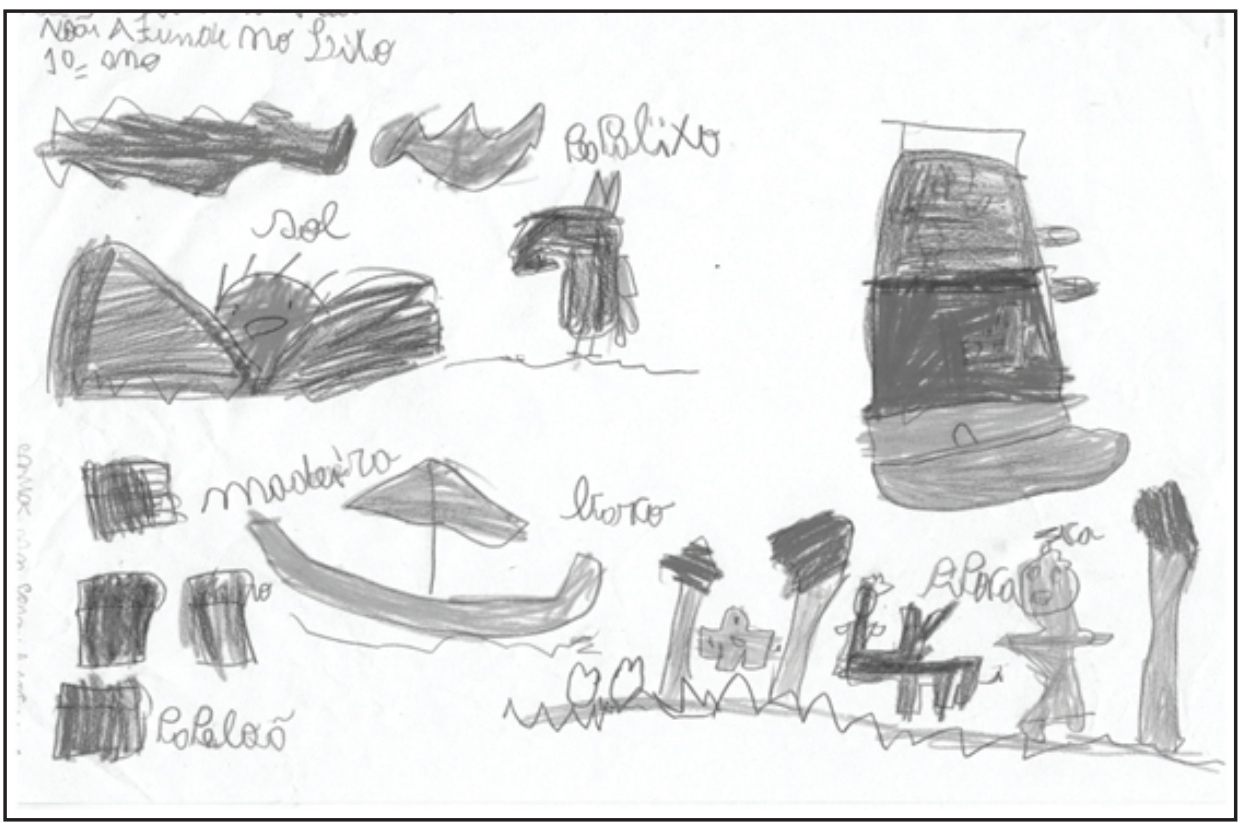

Figura 2 - Coleta de escrita espontânea

Fonte: Relatório de Lagarto, 2015, p. 11.

Essa atividade avaliativa decorreu do projeto pedagógico sobre o lixo urbano e rural e demonstra os saberes de um aluno que expressa suas ideias por meio de palavras e desenhos. Observamos que os alfabetizadores começam a aceitar e valorizar as produções genuínas das crianças, ainda que não cumpram as exigências ortográficas ou a estrutura canônica dos textos. As professoras passaram a compreender que se trata de um processo intersubjetivo e social e, por isso, é difícil e exige compreensão inclusiva e interacional em torno das práticas que envolvem a cultura escrita.

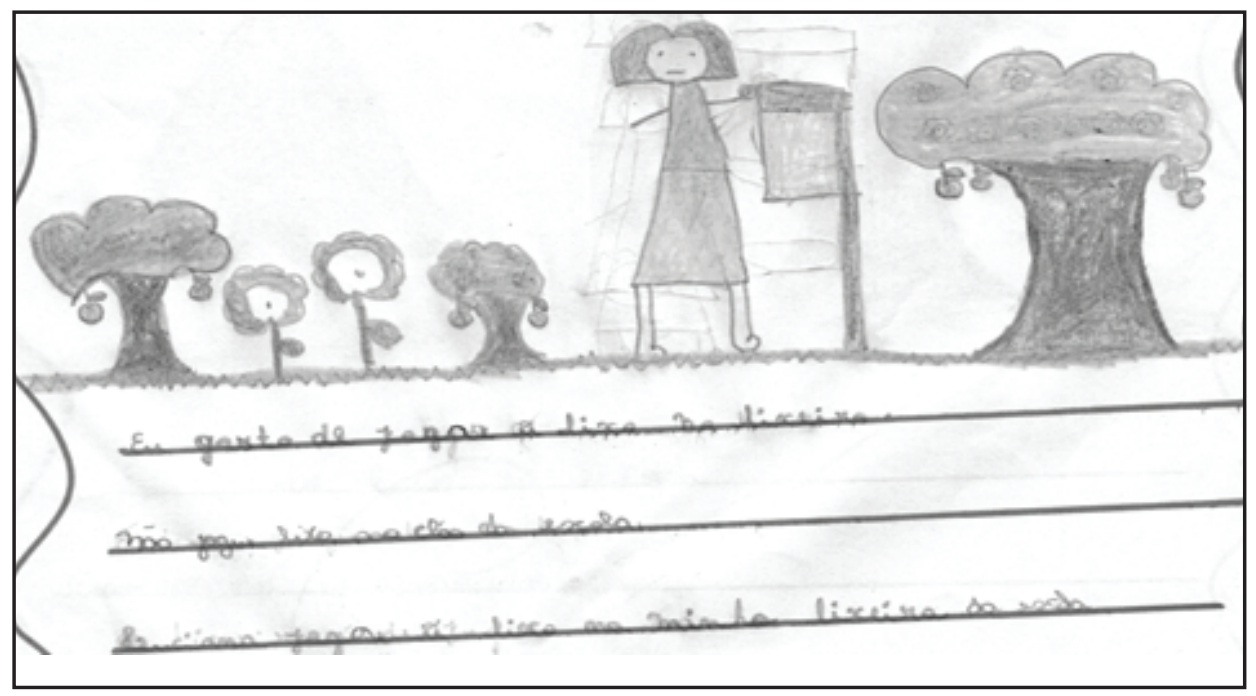

Figura 3 - Produção de texto com base nas atividades do projeto

Fonte: Relatório de Lagarto, 2015, p. 12. 
Observamos que houve uma preocupação de realizar atividades de produção de texto com base em experiências vividas na sala de aula. Tal proposta de trabalho representa um deslocamento das tarefas tradicionais de redação que ofereciam para os alunos apenas o tema para a realização da escrita. Notamos, nesse processo, a necessidade de se trabalhar mais atividades com os gêneros textuais, visto que os textos ainda possuem um formato de frase alinhada, com indefinição do gênero que o aluno se propõe a escrever. A presença dos textos produzidos pelos alunos nos relatórios enviados pelos orientadores de estudo nos forneceram pistas sobre a necessidade de explorar outros aspectos da escrita, voltados para produção de texto sob uma perspectiva discursiva.

Observamos, também, que as atividades avaliativas passaram a ser sistematizadas e com intenção diagnóstica e formativa. No relatório de uma professora alfabetizadora, anexado ao relatório dos orientadores de estudo, ela faz a seguinte avaliação da escrita de seus alunos:

As atividades tiveram início com a apresentação do livro Não afunde no lixo [Bechara, 2011], na qual as professoras o leram e posteriormente os alunos fizeram um debate a respeito do texto e o ilustraram, dando a importância da seleção do lixo, coleta seletiva, os alunos fizeram a formação de palavras através dos códigos, onde relacionaram a cor de cada lixeira seletiva, com os materiais e o lixo orgânico.

As atividades continuaram, e a enfermeira Carolina foi convidada para ministrar uma palestra a respeito das possíveis doenças transmitidas pelo acúmulo do lixo e a poluição dos rios, essa que foi de grande importância, pois nossa comunidade é cortada pelo Rio Machado, onde tem foco de esquistossomose, que é causada por água contaminada. Sabendo disso, os alunos juntamente com os professores e o coordenador saíram pela comunidade, a fim de observar os acúmulos de lixo e, aproveitando o percurso, fomos até o Rio Machado, que os alunos observaram que a água parecia pura, límpida, porém mesmo assim está poluída, pois dejetos de uma boa parte dos domicílios de Lagarto são despejados nesse rio.

Os alunos também aprenderam como reutilizar o lixo, transformando-o em brinquedos, então eles colocaram a mão na massa e produziram brinquedos com garrafas pet, palitos de churrasco, canudos, dentre outros objetos.

Para finalizar as atividades, os alunos produziram cartazes sobre o tema Esporte e fizeram uma apresentação para toda a escola sobre conscientização do meio ambiente, reciclagem do lixo.

As atividades foram bem produtivas e conseguimos fazer com que nossos educadores pudessem formar opiniões próprias e fundamentadas sobre os cuidados e o destino que deve ser dado ao lixo produzido em suas casas. (Relatório de Lagarto, 2015).

Ainda que sem o domínio teórico dos procedimentos de análise sociointeracionista, há uma clara tentativa de analisar o processo de apropriação dos conhecimentos trabalhados na classe de alfabetização de forma interdisciplinar e, também, o exame de como as crianças internalizam os saberes referentes ao domínio da escrita. 


\section{Desenvolvimento dos eixos de leitura, oralidade, produção de texto e análise linguística}

Nesta categoria, podemos verificar que os primeiros relatórios continham expressões bastante generalizadas, tal como se observa a seguir:

Concepção de Alfabetização: O que ensinar no ciclo de alfabetização? Fizemos debate e discussão. Alguns cursistas relataram que anos atrás agiam de uma maneira e hoje mudaram suas atitudes. (Relatório de Amparo de São Francisco, 2013).

É possível inferir que algo estava mudando na percepção dos professores alfabetizadores, ainda que não de forma explícita ou verbalizada, mas já havia o reconhecimento de algo diferente. Não estamos tentando apresentar excesso de otimismo, apenas detectamos um pequeno sinal de que a formação continuada poderia desencadear mudanças nas práticas educativas.

Mais adiante encontramos outras informações sobre as oficinas da categoria em análise:

Prosseguindo foi visto o conceito de alfabetização e de alfabetizar letrando que se sustenta em uma aprendizagem significativa e não é meramente a questão das práticas de leitura e escrita, mas de ter conhecimento e consciência das adversidades dos diferentes gêneros textuais, ser crítico, criativo e autônomo. (Relatório de Simão Dias, 2014).

No trecho acima, os conceitos fundamentais da formação continuada, alfabetização e alfabetizar letrando foram objeto de debate e estudos, pois, sem eles não seria possível o desenvolvimento dos eixos de abordagem da alfabetização na perspectiva do letramento. Portanto, destaca-se o registro da formação com os alfabetizadores atrelada sempre às suas próprias experiências de alfabetizados. Assim, a orientadora de estudo continua:

Abordamos também sobre o SEA sistema de escrita alfabética e a filosofia do currículo inclusivo, respeitando as singularidades, diferenças individuais e de grupos sociais, explicando os direitos gerais de aprendizagem na língua portuguesa, dando ênfase aos quatro eixos: leitura, produção de texto, oralidade, e análise linguística. (Relatório de Simão Dias, 2014).

A compreensão de que a escrita alfabética é um sistema notacional, e não um código, permite ampliar as experiências da produção e da leitura de textos para as crianças do ciclo de alfabetização. Por meio dos gêneros textuais, entende-se o sentido pragmático da escrita e da leitura, pois escrevem-se textos de uso social. Desse modo, foi observado que os professores se apropriaram da prática de planejamento para contemplar os domínios essenciais para o desenvolvimento da língua materna. Neste sentido, nos anexos de um dos relatórios encontramos um exemplo de planejamento feito por uma alfabetizadora (Quadro 1). 
Quadro 1 - Planejamento feito por uma alfabetizadora

\begin{tabular}{|c|c|}
\hline \multicolumn{2}{|c|}{$\begin{array}{ll}\text { Escola Municipal xxxxxx } & \text { Período: } 22 / 05 \text { a 31/05/2013 } \\
\text { Professora: xxxxxx } & \text { Turma: } 1^{\circ} \text { ano A } \\
\text { Título do livro escolhido: O casamento de dona Baratinha } \\
\text { Autor e editora: Ana Maria Machado }\end{array}$} \\
\hline $\begin{array}{c}\text { Eixo de língua } \\
\text { portuguesa }\end{array}$ & Descrição da proposta de trabalho \\
\hline Oralidade & $\begin{array}{l}\text { - Imitar as "falas" dos personagens; } \\
\text { - Alunos criam oralmente um novo final para o conto; } \\
\text { - Interpretar a história oralmente; } \\
\text { - Dramatizar o conto "O casamento de D. Baratinha". }\end{array}$ \\
\hline Leitura & $\begin{array}{l}\text { - Criar suspense no dia anterior sobre a protagonista: } \\
\text { "Quem será que vai chegar amanhã?"; } \\
\text { - Apresentar a história em capítulos, como uma novela; } \\
\text { - Distribuir cópias dos capítulos para os alunos, } \\
\text { conforme o desenrolar do enredo e sugerir que pintem } \\
\text { as gravuras; } \\
\text { - Ler junto com eles, várias vezes, pedir que eles } \\
\text { marquem palavras, frases e rimas; } \\
\text { - O professor lê uma frase e os alunos em dupla, } \\
\text { identificam-na. }\end{array}$ \\
\hline Produção de texto & $\begin{array}{l}\text { - Reproduzir as falas dos animais (ditado de falas); } \\
\text { - Apresentar outra versão para história, modificando o } \\
\text { seu final, o professor vai copiando no quadro } \\
\text { e os alunos transcrevendo no caderno; } \\
\text { - Criar um novo título para a história; } \\
\text { - Confeccionar junto com a professora, as máscaras das } \\
\text { personagens (Artes); } \\
\text { - Criar um convite para o casamento da D. Baratinha; } \\
\text { - Trabalhar com atividades de recorte, jogo dos erros, } \\
\text { montagem do texto, texto enigmático, cruzadinhas } \\
\text { etc. }\end{array}$ \\
\hline Análise linguística & $\begin{array}{l}\text { - Trabalhar encontros vocálicos a partir das falas } \\
\text { das personagens; } \\
\text { - Identificar as rimas nos versos; } \\
\text { - Letra inicial e final de palavras-chave do texto; } \\
\text { - Separação de sílabas e contagem das mesmas; } \\
\text { - Quantidade de palavras de uma estrofe do conto; } \\
\text { - Embaralhar os versos e pedir que eles os ordenem. }\end{array}$ \\
\hline
\end{tabular}

Fonte: Relatório de Simão Dias, 2014. 
Ainda que muitas questões relacionadas ao funcionamento da linguagem verbal no plano discursivo não tenham sido levadas em conta, percebe-se uma preocupação com um ensino de língua materna de maneira interligada. Observa-se que os eixos propostos para a alfabetização na perspectiva do letramento foram planejados a partir de textos reais, contemplando atividades de compreensão do texto e de análise linguística.

Para finalizar, vale destacar que, em seu último ano de sobrevivência, o processo de formação continuada do PNAIC-UFS, desenvolveu um projeto denominado Brincar, brincadeiras, infância e criança no ciclo de alfabetização. Na concepção desse projeto, defendia-se que as crianças pequenas, em suas infâncias, no espaço-tempo produtor de cultura, constituem-se de saberes próprios e são capazes de criar e recriar a realidade social na qual estão inseridas. Tal concepção não fora apenas um desiderato pedagógico, mas um fundamento da educação da infância em seu processo de requalificação e criação de identidade do ciclo de alfabetização. Dessa maneira, o tema foi discutido pelos orientadores de estudo com os professores, com relata o trecho a seguir:

\footnotetext{
Dando continuidade, foi ministrada uma leitura deleite de um texto sobre o resgate de lembranças de infância (memória de infância ${ }^{5}$ ) em que cada profissional pudesse navegar de forma prazerosa no seu tempo de infância, logo após foi realizada uma dinâmica coletiva ajustando o trabalho com (jogos de brincadeiras), dando ênfase ao desempenho de como alfabetizar brincando, tomando como ponto fundamental o aprender participando, o ler executando e o fazer na prática, porque é desta forma que vamos despertar o interesse dos nossos alunos, a fim de obtermos um aprendizado com compreensões coerentes que assegure uma preparação para o futuro e que prepare cada cidadão com consciência podendo conviver com dignidade inserida na sociedade. (Relatório de Tomar de Geru, 2015).
}

A infância dos professores alfabetizadores, reatada com a infância de seus pequenos estudantes, ganha a dignidade do cuidado elevada à dignidade política do direito à educação. Assim, o espaço da sala de aula passou a ser ocupado de diferentes formas.

Observamos que, ao construírem seus próprios conhecimentos,os alfabetizadores se reencontram com suas infâncias e se aproximam das crianças, que esperam ser ativadas em todas as suas capacidades físicas, intelectuais, imaginativas e emocionais, tão próprias da criança em sua singularidade e universalidade.

\section{Considerações finais}

Ao procurar cumprir o principal objetivo deste relato, analisamos que o recorte pedagógico e os critérios de seleção dos relatórios dos orientadores de estudo trazem elementos da totalidade da realidade observada, resguardando suas singularidades e especificidades.

\footnotetext{
${ }^{5}$ O livro Guilherme Augusto Araújo Fernandes, da escritora australiana Mem Fox (1996).
} 
A principal compreensão que se pode extrair da implantação dessa política educacional é a fundamental importância da formação continuada para que os saberes docentes sejam revistos, repensados e assimilados em diálogo constante com as teorias pedagógicas, com os pesquisadores das universidades e, especialmente, com os próprios pares.

As transformações operadas na prática de ensino são visíveis na medida em que os professores alfabetizadores expressam as diferenças entre suas ações anteriores e posteriores à formação. Ainda que não tenha sido verbalizado explicitamente nos relatórios dos orientadores de estudo, percebe-se que a ação demarca um divisor de águas entre os procedimentos da alfabetização, como codificação e decodificação para uma perspectiva de letramento. Observamos, também, que se passou a olhar para a escrita infantil com tendência a compreender as razões cognitivas das crianças e, a partir de seu nível de compreensão, criar intervenções que possam fazê-las avançar em seu processo.

Outro aspecto a se destacar é que, apesar das precariedades materiais, estruturais e pedagógicas, os encontros realizados entre os orientadores de estudo e os professores alfabetizadores constituíram laços de apoio e solidariedade na importante tarefa de alfabetizar uma turma de crianças do primeiro ciclo. Isso é sentido diretamente na sala de aula, pois levavam sugestões de práticas de ensino, além do que fora formulado no campo mais abstrato da teoria, e traziam os resultados de seus trabalhos com os alunos, resultados esses que se multiplicavam em diferentes formas de tratar pedagogicamente a construção da escrita dos pequenos estudantes.

Em síntese, ainda que a formação continuada não tenha a condição de solucionar eventuais problemas da formação inicial, pode-se afirmar que essa experiência sacudiu a letargia das viciadas práticas de alfabetização, pois, por meio dos relatórios é possível perceber as ressignificações que os docentes fazem de si, de suas práticas, de suas crianças, de suas produções e do tempo e espaço da sala de aula.

\section{Referências bibliográficas}

BECHARA, Nilce. Não afunde no lixo. Birigui: Liberty, 2011.

(PNLD 2013/2014/2015).

BRASIL. Constituição (1988). Constituição da República Federativa do Brasil. Texto constitucional promulgado em 5 de outubro de 1988, com as alterações determinadas pelas Emendas Constitucionais de Revisão nos 1 a 6/94, pelas Emendas Constitucionais nos 1/92 a 91/2016 e pelo Decreto Legislativo no 186/2008. Brasília: Senado Federal, Coordenação de Edições Técnicas, 2016. 496 p. Disponível em: < https://www2.senado.leg.br/bdsf/bitstream/handle/ id/518231/CF88_Livro_EC91_2016.pdf?sequence=1>; <http://www.planalto.gov. br/ccivil_03/constituicao/constituicaocompilado.htm >.

BRASIL. Lei n¹3.005, de 25 de junho de 2014. Estabelece o Plano Nacional de Educação - PNE, e dá outras providências. Disponível em: < http://www. planalto.gov.br/CCIVIL_03/_Ato2011-2014/2014/Lei/L13005.htm>. Acesso em: 23 out. 2016. 
BRASIL. Lei no 9.394, de 20 de dezembro de 1996. Estabelece as diretrizes e bases da Educação Nacional. Diário Oficial da União, Brasília, 1996. Disponível em: <http://www.planalto.gov.br/ccivil_03/leis/L9394.htm>.

BRASIL. Fundo Nacional de Desenvolvimento da Educação (FNDE). Resolução FNDE/CD n $n^{\circ}$ 24, de 16 de agosto de 2010. Estabelece orientações e diretrizes para o pagamento de bolsas de estudo e de pesquisa a participantes dos programas de formação inicial e continuada de professores e demais profissionais de educação, implementados pela Secretaria de Educação Básica do Ministério da Educação (SEB/MEC) e pagas pelo FNDE. Disponível em: < http://www.fnde. gov.br/fnde/legislacao/resolucoes/item/3406resolu\%C3\%A7\%C3\%A3o-cd-fnden\%C2\%BA-24-de-16-de-agosto-de-2010 > .

BRASIL. Instituto Nacional de Estudos e Pesquisas Educacionais Anísio Teixeira (Inep). Mapa do analfabetismo no Brasil. Brasília, [2002?]. Disponível em: < http://portal.inep.gov.br/documents/186968/485745/ Mapa + do + analfabetismo + no + Brasil/a53ac9ee-c0c0-4727-b216035c65c45e1b?version=1.3>. Acesso em: 12 set. 2012 .

BRASIL. Ministério da Educação (MEC). Secretaria de Educação Básica (SEB). Pacto Nacional pela Alfabetização na Idade Certa: formação do professor alfabetizador caderno de apresentação. Brasília: MEC, SEB, 2012a. 40 p. Disponível em: http://pacto.mec.gov.br/images/pdf/Formacao/Apresentacao\%20MIOLO.pdf

BRASIL. Ministério da Educação (MEC). Secretaria de Educação Básica (SEB). Pró-Letramento: Programa de Formação Continuada de Professores dos Anos/Séries Iniciais do Ensino Fundamental - guia geral. Brasília: MEC, 2012b. Disponível em: http://portal.mec.gov.br/index.php?option=com docman\&view=download\&alias=6268-guiageral-1\&category_slug=julho-2010pdf\&Itemid $=301924$

BRASIL. Ministério da Educação (MEC). Portaria no 867, de 4 de julho de 2012. Institui o Pacto Nacional pela Alfabetização na Idade Certa e as ações do Pacto e define suas diretrizes gerais. Diário Oficial da União, n. 129, Seção 1, p. 22-23, 5 jul. 2012. Disponível em: <http://pacto.mec.gov.br/images/pdf/port_867_040712.pdf>.

FOX, Mem. Guilherme Augusto Araújo Fernandes. Tradução de Gilda de Aquino. Ilustração de Julie Vivas. São Paulo: Brinque-Book, 1996.

GUEDES-PINTO, Ana Lúcia; LEAL, Telma Ferraz. Avaliação para inclusão: alfabetização para todos. In: PACTO Nacional pela Alfabetização na Idade Certa: currículo inclusivo - o direito de ser alfabetizado, ano 03, unidade 01. Brasília, DF: MEC/SEB, 2012. p. 22-27. Disponível em: http://pacto.mec.gov.br/images/pdf/ Formacao/Ano_3_Unidade_1_MIOLO.pdf

SERGIPE. Secretaria do Estado de Planejamento, Orçamento e Gestão (Seplag). Territórios de planejamento. Disponível em: < htpp://www.Observatorio.se.gov.br/ images/Geografia_e_Cartografia/divisão_administrativa_e_RegionalizacOE/Mapa_ dos_Territórios_Sergipanos>. Acesso em: 1 ago. 2016. 
Silvana Aparecida Bretas, doutora em Educação Escolar pela Universidade Estadual Paulista "Júlio de Mesquita" (Unesp) campus de Araraquara, é professora associada do Departamento de Educação e do Programa de Pós-Graduação em Educação da Universidade Federal de Sergipe (UFS).

s-bretas@uol.com.br

José Ricardo Carvalho, doutor em Letras pela Universidade Federal Fluminense (UFF), é professor associado do Departamento de Educação e do Programa de Pós-Graduação em Letras da Universidade Federal de Sergipe (UFS). Atua como coordenador geral do Pacto Nacional pela Alfabetização na Idade Certa (PNAIC) em Sergipe, desde 2012.

ricardocarvalho.ufs@hotmail.com

\section{Anexo \\ Relatórios analisados}

AMPARO DE SÃO FRANCISCO. Relatório da Unidade 1: auto-avaliação. 2013. [Não publicado].

CANINDÉ DE SÃO FRANCISCO. Relatório da Unidade 2: auto-avaliação. 2013a. [Não publicado].

CANINDÉ DE SÃO FRANCISCO. Relatório Unidade 1, 2 e 3: oficinas pedagógicas. 2013b. [Não publicado].

FEIRA NOVA. Relatorio da Unidade 1 e 2. 2013a. [Não publicado].

FEIRA NOVA. Relatório Unidade 1, 2 e 3: oficinas pedagógicas. 2013b. [Não publicado].

ITABAIANA. Relatório da formação de alfabetizadores em Itabaiana da unidade IV em alfabetização Matemática em perspectiva do letramento. 2014. [Não publicado].

LAGARTO. Relatório dos Cadernos 1 e 2. 2015. [Não publicado].

NOSSA SENHORA DO SOCORRO. Encontro de formação PNAIC - Pacto Nacional pela Alfabetização na Idade Certa: Relatório da Unidade I. 2013. [Não publicado].

SIMÃO DIAS. Relatório. 2014. [Não publicado].

TOMAR DE GERU. Unidade II. 2015. [Não publicado]. 